\title{
Limited Attention and Income Distribution
}

\section{Citation}

Banerjee, Abhijit V. and Sendhil Mullainathan. 2008. Limited attention and income distribution. American Economic Review 98, no. 2: 489-493.

\section{Published Version}

http://dx.doi.org/10.1257/aer.98.2.489

\section{Permanent link}

http://nrs.harvard.edu/urn-3:HUL.InstRepos:2907518

\section{Terms of Use}

This article was downloaded from Harvard University's DASH repository, and is made available under the terms and conditions applicable to Open Access Policy Articles, as set forth at http:// nrs.harvard.edu/urn-3:HUL.InstRepos:dash.current.terms-of-use\#OAP

\section{Share Your Story}

The Harvard community has made this article openly available.

Please share how this access benefits you. Submit a story.

\section{Accessibility}




\title{
Limited Attention and Income Distribution
}

\author{
Abhijit Banerjee (Corresponding Author) \\ Massachusetts Institute of Technology \\ E-52, 252d \\ 50 Memorial Drive \\ Cambridge, MA 02142 \\ 617-253-8855 (phone) \\ 617-253-6915 (fax) \\ banerjee@mit.edu \\ Sendhil Mullainathan \\ Department of Economics \\ Littauer 208 \\ Harvard University \\ Cambridge, MA 02138 \\ and NBER \\ 617-496-2720 (phone) \\ 617-495-7730 (fax) \\ mullain@fas.harvard.edu
}

\section{AEA Session Title, Chair and Discussant}

Jan. 4, 2:30pm, AEA, "Psychology and Development: Theory and Experimental Evidence"

Chair: Sendhil Mullainathan, Harvard University

Discussants: Emir Kamenica, University of Chicago GSB

Colin Camerer, Caltech Institute of Technology 


\title{
Limited attention and income distribution
}

\author{
Abhijit V. Banerjee and Sendhil Mullainathan*
}

Economists have long been interested in the idea that there is a direct circular relation between poverty and low productivity, and not just one that is mediated by market failures, usually in asset markets. The nutrition-based efficiency wage model (Partha Dasgupta and Debraj Ray, 1987) is the canonical example of models where this happens: However it has been variously suggested (see for example T. N. Srinivasan, 1994) that the link from nutrition to productivity and especially the link from productivity to nutrition is too weak to be any more than a small part of the story. Partha Dasgupta himself acknowledges this when he writes "nutrition-productivity construct provides a metaphor,..., for ... an economic environment harboring poverty traps" (Partha Dasgupta, 1997, page 5).

We propose an alternative approach to this question based on the idea that attention is a scarce resource that is important for productivity. Specifically, people may not be able to fully attend to their jobs if they are also worrying about problems at home and being distracted in this way reduces productivity. But not paying attention at home is also costly: early symptoms of a child's sickness may go unnoticed; water may run out at the end of the day; kerosene for lighting lamps at home might run out and make it hard to do homework; etc. Finally, the extent to which home life distracts depends on the nature of 
home life. Specifically, certain goods (e.g. a good baby sitter, a 24-hour piped water supply, a connection to a power supply grid) can reduce the extent of home life distraction.

These three assumptions generate an interesting relation between income and productivity that is at the core of our model. The non-poor in this model, by virtue of owning distraction-saving goods and services at home, are able to focus more on their work. Hence they will be more productive at work and will be able to afford more distraction-saving goods. This simple two-way relationship between income and productivity produces a discontinuity in the relation between human capital and earnings which is certain cases can lead to a poverty trap, even in the absence of any market failures.

\section{The Model}

\section{I.1 Set Up.}

A consumer can consume two types of goods: food $f$ and comfort goods $c$, each costing unit price. Normally they provide Cobb-Douglas utility $c^{\alpha} f^{1-\alpha}$. With some probability $p_{h}$ however there is a problem at home which reduces this utility by $b-c$. Paying attention at home reduces the cost of the problem: Specifically, when $\theta$ units of attention are paid at home, problems are caught with probability $\theta$. Problems caught early are assumed to have no cost. Putting $1 \mathrm{l}$ this together suggests total utility is: $c^{\alpha} f^{1-\alpha}-p_{h}(1-\theta)(b-c)$. The second term is the probability of problem $\left(p_{h}\right)$ that is uncaught $(1-\theta)$ multiplied by the cost of uncaught problems $(b-c)$. To avoid dealing with what happens when $c>b$, we will assume that in the relevant range of $c, b-c$ is always positive 
Individuals are endowed with human capital $h$ which they use at work to earn income. Absent a problem at work output equals $h$. Problems arise with probability $p_{w}$ and reduce output by a fraction $1-\beta$ if unnoticed. If an individual is attentive at work, problems are caught and have no effect on output. For example, while milking an animal, an attentive worker may notice the early signs of disease. The key to our model is that the amount of attention a worker can pay at work depends on the attention he pays at home. For simplicity, we model this distraction in an extreme way: the amount of attention available for work is $1-\theta$, where $\theta$ is the attention used up at home. Given attentiveness $1-\theta$ at work, problems are caught with probability $1-\theta$. Thus output as a whole is $h\left(1-p_{w} \theta(1-\beta)\right)$. Which reflects the fact that a problem must arise (probability $p_{w}$ ) be uncaught (probability $\theta$ ) to reduce output (by fraction $1-\beta$ ). We assume that problems at home and problems at work arise independently.

The individual's income $y$, it is assumed, equals the expected output that is the result of the choice of $\theta$. This presumes that $\theta$ is contractable: the employee promises the employer (or an insurance company) a particular value of $\theta$ and in return for full insurance. In a companion paper we discuss, among other things, the case where $\theta$ is not contractable (see Abhijit Banerjee and Sendhil Mullainathan (2008)).

The time line is as follows: the person first picks $c$ and then selects $\theta$. Then problems at home and at work occur and are either detected or not. Then output is realized. We assume perfect credit markets, and $\theta$ is contractable so it does not matter whether he gets his income at the beginning or after output is realized. 


\section{I.2 Optimization}

Since the consumer spends all income on one of the two goods, he therefore maximizes

$$
\operatorname{Max}_{c} c^{\alpha}(y-c)^{1-\alpha}-p_{h}(1-\theta)(b-c)
$$

Subject to the constraint

$$
y=h\left(1-p_{w} \theta(1-\beta)\right)
$$

The first order condition with respect to $c$ is:

$$
(1-\alpha)\left(\frac{c}{y-c}\right)^{\alpha}-\alpha\left(\frac{y-c}{c}\right)^{1-\alpha}=p_{h}(1-\theta)
$$

Several basic facts that follow from this first order condition. First, the optimal amount of comfort good is simply a fraction of income. This can be seen by simply noting that $c=m y$ satisfies the first order condition, combined with the fact that the maximand is strictly concave and therefore has a unique maximizer. Therefore write $c\left(\theta, p_{h}, y\right)=m\left(\theta, p_{h}\right) y$. Second, conditional on $y$, comfort good consumption is decreasing in $\theta$. To see why, note that since $c=m y$, the left hand side of the above first order condition does not depend directly on $\theta$ but is increasing in $m\left(\theta, p_{h}\right)$. The right hand side however is decreasing in $\theta$. For the two sides to remain equal, $m$ must go down when $\theta$ goes up. This is a key feature of our model: comfort goods and attention towards home are substitutes. Finally, note that because $c$ is proportional to $y$, total utility is linear in $y$.

The previous analysis took $\theta$ as given. What determines the choice of $\theta$ ? It will be useful to define $U$ to be the total utility at the optimum given the exogenous parameters. Defining $U(\theta)$ to be $c\left(\theta, p_{h}, y\right)^{\alpha}\left(y(\theta)-c\left(\theta, p_{h}, y\right)\right)^{1-\alpha}-p_{h}(1-\theta)\left(b-c\left(\theta, p_{h}, y\right)\right)$ The envelope theorem 
gives us that

$$
\begin{aligned}
\frac{d U(\theta)}{d \theta} & =(1-\beta) h p_{w}(1-\alpha)\left(\frac{c\left(\theta, p_{h}, y\right)}{y(\theta)-c(\theta, y)}\right)^{\alpha}+p_{h}\left(b-c\left(\theta, p_{h}, y\right)\right) \\
& \left.=-(1-\beta) h p_{w}(1-\alpha)\left(\frac{m\left(\theta, p_{h}\right)}{1-m\left(\theta, p_{h}\right)}\right)^{\alpha}+p_{h}\left(b-m\left(\theta, p_{h}\right) y(\theta)\right)\right)
\end{aligned}
$$

Increasing $\theta$ has two effects on $U$ : (i) it decreases utility by decreasing income and thereby overall consumption and (ii) it increases utility by increasing the chance of stopping a problem at home. What is the shape of $U(\theta)$ function? Rewrite 1

$$
\alpha\left(\frac{1-m\left(\theta, p_{h}\right)}{m\left(\theta, p_{h}\right)}\right)^{1-\alpha}+p_{h}(1-\theta)=(1-\alpha)\left(\frac{m\left(\theta, p_{h}\right)}{1-m\left(\theta, p_{h}\right)}\right)^{\alpha} .
$$

Clearly $(1-\alpha)\left(\frac{m\left(\theta, p_{h}\right)}{1-m\left(\theta, p_{h}\right)}\right)^{\alpha}$ must go down when $\theta$ goes up. Using this fact and the fact that $m\left(\theta, p_{h}\right)$ and $y(\theta)$ are both decreasing in $\theta$, it is clear that $\frac{d U}{d \theta}$ must go up when $\theta$ goes up. In other words, $\frac{d^{2} U}{d \theta^{2}}>0$. Therefore there cannot be an interior optimum in $\theta$. In other words, the maximization problem has a "bang-bang" solution: either the individual pays full attention at home $(\theta=1)$ or full attention at work $(\theta=0)$.

This is a key result and is worth understanding well: Paying more attention at home makes the person poorer and therefore less able to buy comfort goods. But having less comfort goods makes the problems at home worse and this makes it even more important to pay more attention at home. This makes the optimization problems non-convex and produces a "bang-bang' solution despite the fact that both the work and the home production functions are linear as a function of $\theta$.

What determines the choice between $\theta=0$ and $\theta=1$ ? The condition for choosing $\theta=0$ is simply that the person is better off there than at $\theta=1$, i.e.:

$h\left(m\left(0, p_{h}\right)\right)^{\alpha}\left(1-m\left(0, p_{h}\right)\right)^{1-\alpha}-p_{h}\left(b-m\left(0, p_{h}\right) h\right) \geq h\left(m\left(1, p_{h}\right)\right)^{\alpha}\left(1-m\left(1, p_{h}\right)\right)^{1-\alpha}\left(1-p_{w}(1-\beta)\right)$. 


\section{Implications for income distribution}

It follows immediately from writing 5 in the form:

$\left(m\left(0, p_{h}\right)\right)^{\alpha}\left(1-m\left(0, p_{h}\right)\right)^{1-\alpha}-p_{h}\left(\frac{b}{h}-m\left(0, p_{h}\right)\right) \geq\left(m\left(1, p_{h}\right)\right)^{\alpha}\left(1-m\left(1, p_{h}\right)\right)^{1-\alpha}\left(1-p_{w}(1-\beta)\right)$

that people with higher $h$ will choose $\theta=0$ all else being the same.Moreover for $h$ close to zero $\theta=1$ clearly dominates, while for $h$ high enough $\theta=0$ will be chosen. Also by our assumption that in the relevant range of $h, b-m\left(0, p_{h}\right) h>0$, it follows that for any particular value of $h$, if $\theta=1$ is chosen at any value of $p_{h}$, it will be chosen at all higher values of $p_{h}$. We summarize this observation in

Proposition 1 For any fixed value of $p_{h}$ there will exist a threshold $\bar{h}^{c}\left(p_{h}\right)$ such that when $h \geq h^{c}\left(p_{h}\right)$ people who face a probability $p_{h}$ of problems at work will pay full attention at work. When $h<h^{c}\left(p_{h}\right)$ they are inattentive at work. Also if for some combination of $p_{h}$ and $h, \theta=1$ is chosen, then there exists a critical value of $p_{h}(h), p_{h}^{c} \in(0,1)$ such that for $p_{h} \leq p_{h}^{c}(h), \theta=1$ will be chosen by somone with human capital h but not otherwise

The first part of this says that richer people (i.e. people who start with a higher level of human capital) will be pay more attention at work, which further boosts their income. As a result while utility is continuous in $h$, there is a critical level of human capital where income jumps discretely up and returns to human capital are convex, at least over a range. This bifurcation is the core of this paper.The rich, by being able to afford more comfort goods, increase their productivity and incomes even more than the poor. Thus, even with a linear 
production function and perfect credit markets, we have recreated the basic elements of a poverty trap. Note however that in this view, it is income, not utility, where there is a jump. So those right above and below the threshold earn very different amounts but have similar utility. The second part says that those who have more serious problems at home will be less productive. Moreover an alternative interpretation of a higher value of $p_{h}$ is that there are more problems at home that you care (and hence worry) about. This, combined with the discontinuity in productivity suggest women's earnings (though not their utility levels) might be substantially lower than men's earnings for the same level of human capital, just because women care slightly more about problems at home. In a simple extension of the model it can also be shown that those who are better at solving problems at home will have lower productivity.

\section{Infrastructure and Productivity}

The switch from $\theta=0$ to $\theta=1$, is accompanied by a jump in productivity. Hence this model has a number of implications for productivity comparisons across countries. First, one of the important sources of problems at home could be lack of access to quality infrastructure. For example, unreliable electricity or water supply create the need for paying more attention towards what is going on at the home. By providing more reliable public goods (i.e a lower $p_{h}$ ) countries therefore not only make people better off in welfare terms but also generate higher productivity. Similarly better access to a power grid or a water-line might increase productivity of the labor force. Of course in either case, these gains would need weighed against the costs, but suggests an additional channel through which infrastructural 
improvement can benefit productivity and growth. Second, countries where the average worker is better paid will have more productive workers: in other words, this will be true even if the difference in pay has nothing to do with productivity. More generally there is a virtuous cycle that runs from higher productivity to higher pay to even higher productivity.

\section{Occupational Choice}

The results so far presume that there is only one job available. It is natural, however, to examine the sorting consequences of distraction. Imagine there are two potential jobs available. One job (the high responsibility job) is more productive but suffers more from distraction. This job produces $\tau h$ where $\tau>1$ and has probability $p_{w}$ of failures which cots a fraction $\beta$ of output. The other (the low responsibility job) is less productive but suffers less from distraction. It has output equal to $h$ but has no chance of failures. Suppose that the worker first chooses a job and then choose $\theta$. Assume that $(\tau-1)<p_{w}(1-\beta) \tau$, . Under this assumption it is worth noting that at low levels of attention to work $1-\theta=0$ the low responsibility job produces more output and would be chosen. On the other hand because $\tau>1$, at full attention to work $(1-\theta=1)$ the high responsibility job produces more output and would be chosen. This type of reasoning combined with the argument behind Proposition 1 implies:

Proposition 2 If there is a high responsibility high productivity job and a low responsibility low return job, there will be a threshold $h^{\prime}$ such that people with $h \geq h^{\prime}$ people will choose the high responsibility job and pay full attention at work while those with $h<h^{\prime}$ individuals will choose the low responsibility job and pay less than full attention at work. 
This says that the reason we observe people with low human capital specializing in industries like agriculture may be that the margin of error in agriculture tends to be relatively large (with most crops small delays in when you water them or when you put in fertilizer does not matter too much), which allows them to focus on problems of home life.

A simple extension of the model also predicts that people with low levels of human capital or high sensitivity to problems at home would select into occupations where they are in a position to easily solve problems at home. Thus women might select into low productivity occupations that offer them the option of be close to home

\section{Income dynamics}

This section draws out the dynamic consequences of Proposition 1, which says that small differences in human capital can have large consequences for income.

We now show that in an inter-generational model these inequalities translate into persistent income differences. Assume that people get human capital from their parents: A fraction $\gamma$ of the amount of food consumed by their parents goes to the children and their human capital is a multiple $\eta$ of the amount of food that was allocated to them plus a constant $\sigma$.

For production make the assumptions we made for the two jobs model in the last section: The result in that model was that those who have low $h$ choose the low responsibility job while the rest choose the high responsibility job. In equilibrium neither job carries any risk since the former is inherently risk-less and the latter is only chosen by people who give it full attention. Denote by $h^{c}$ the value of $h$ where the switch happens. Hence the 


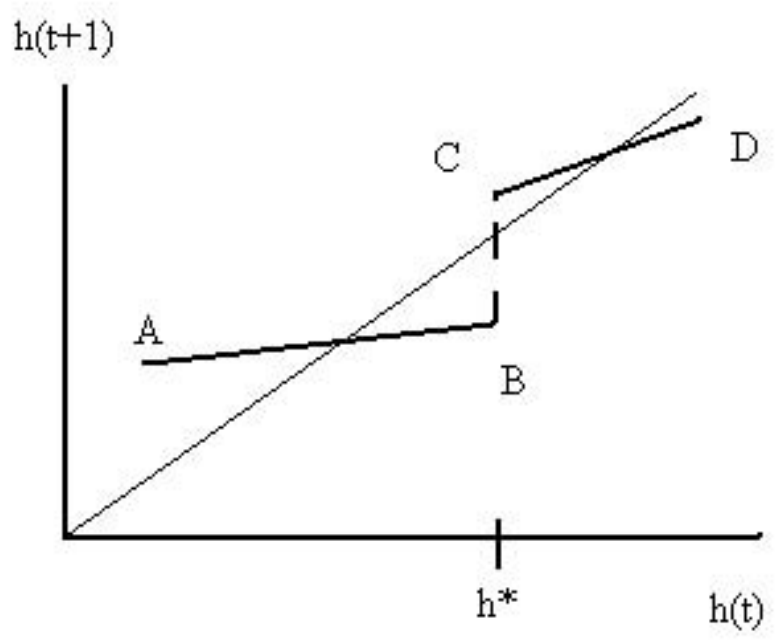

Figure 1: Human Capital Dynamics

inter-generational dynamics of human capital can be written as:

$$
\begin{aligned}
h_{t+1} & =\sigma+\eta \gamma\left(1-m\left(1, p_{h}\right)\right) h_{\tau} \text { for } h<h^{c} \\
& =\sigma+\eta \gamma\left(1-m\left(0, p_{h}\right)\right) \tau h_{\tau} \text { for } h \geq h^{c}
\end{aligned}
$$

These dynamics are represented in figure 1 for the case where $\left(1-m\left(0, p_{h}\right)\right) \tau>\cdot\left(1-m\left(1, p_{h}\right)\right)$ (it is easily checked that this case is possible). The line through the origin has a slope of 1: It represents the equation $h_{t+1}=h_{t}$. The broken line with a jump at $h^{*}$ represents the dynamics of $h_{t}$. The line $\mathrm{AB}$ represents the equation $h_{t+1}=\sigma+\eta \gamma\left(1-m\left(1, p_{h}\right)\right) h_{\tau}$ while the line CD represents the equation $\sigma+\eta \gamma\left(1-m\left(0, p_{h}\right)\right) \tau h_{\tau}$. Clearly, as drawn, there are two stable steady state values of $h$ : those dynasties that start low converge to the lower value while those who start high stay high. In other words, there is a poverty trap here despite the fact that all markets work perfectly.

For simplicity, we assumed a specific the bequest prreference to get this result. Because children's utility does not directly enter parental preferences, we ignore the possibility that parents may spend extra to help children acquire additional human capital. However the 
presence of a discontinuity implies that a poverty-trap could exist even if parents did care about their children's welfare.

\section{Conclusion}

This paper introduces a simple model of how home life and work life interact through limited attention with important implications for the distribution of income. While distractions and deviations from rationality are obviously related, our model does not rely on any of these deviations. Instead, the psychological insights help us motivate a richer preference structure within a rational choice model. In fact our model is formally identical to a rational timeallocation, if we think of comfort goods as time-saving devices. In other words, our result could be read as saying that time spent working jumps up as human capital goes up. However according to Abhijit Banerjee and Esther Duflo (2008), the evidence that the poor work less hours than the non-poor tends to be patchy and the differences in hours worked tend to be small. If time-use has to be a significant part of the explanation of the observed differences, it must be the quality of time-use (i.e. attention) rather than the quantity, that matters.

\section{Notes}

*Departments of Economics, Massachusetts Institute of Tecnology and Harvard University; Addresses: 252d, 50 Memorial Drive, Cambridge MA 02142 and Littauer Center M18, Harvard University, Cambridge MA 02138; banerjee@mit.edu and mullain@fas.harvard.edu. We thank Emir Kamenica for valuable comments. 


\section{References}

Banerjee, Abhijit and Esther Duflo, "What is middle class about the middle classes around the world?", forthcoming, Journal of Economic Perspectives, 2008.

Banerjee, Abhijit and Sendhil Mullainathan, "Economic Consequence of Limited Attention," in progress, 2008.

Dasgupta, Partha and Debraj Ray, "Inequality as a Determinant of Malnutrition and Unemployment:Theory," Economic Journal 96, 1011-1034, 1986.

Dasgupta, Partha, "Nutritional Status, the Capacity for Work and Poverty Traps." Journal. of Econometrics 77(1): 5-38, 1997.

Srinivasan, T. N. "Destitution: A Discourse." Journal of Economic Literature, 32, 4, 1842-55, 1994. 